\title{
Spatial Thinking in Children's Education: The relationship between Geography and Cartography
}

\author{
Paula Cristiane Strina Juliasz ${ }^{\mathrm{a},}$, , Sonia Maria Vanzella Castellar ${ }^{\mathrm{b}}$ \\ ${ }^{a}$ Universidade Federal Fluminense - UFF 1, paulacsj@id.uff.br, \\ ${ }^{b}$ Universidade de São Paulo - USP, smvc@ usp.br \\ * Corresponding author
}

\begin{abstract}
Spatial thinking, comprised of concepts, representations and spatial abilities, is a cognitive activity developed in everyday living, and can be systematized through different school disciplines, mainly Geography. The comprehension of this concept and the investigation of how it can be developed and systematized in schools are critical points, involving different languages that represent the space. Our main objective is to propose theoretical and methodological references for the spatial knowledge of children aged between 4 and 6 years old. The research is based on the following question: Which spatial abilities and concepts can be addressed in activities aimed at developing spatial thinking in children aged 4 to 6 years old? To answer this question and achieve the main objective, the specific objectives were: a) to investigate and analyze the pertinence, possibilities and approaches regarding the spatial notions in children's education; b) develop teaching situations based on guiding theories about spatial thinking, children's drawing and the concept construction under a historical and cultural perspective; c) understand the patterns in children's graphic representations; and d) analyze the children's dialogues. The analysis of the research data allowed us to conclude that drawing is part of the cartographic initiation, and words are fundamental elements that concretize the way of thinking, in this case, spatial thinking ability. In this research, we reaffirm the direct relationship between Geography and the development of spatial thinking, considering the very nature of this Science, and Cartography as the language used to materialize this way of thinking.
\end{abstract}

Keywords: spatial thinking, children's education, geography, school cartography

\section{Introduction}

\subsection{General Instructions}

Spatial thinking, comprised of concepts, representations and spatial abilities, is a cognitive activity developed in everyday living, and can be systematized through different school disciplines, mainly Geography. The comprehension of this concept and the investigation of how it can be developed and systematized in schools are critical points, involving different languages that represent the space.

The objective of this paper is to present the investigation paths and the role of language and intentional activities based on historical and cultural theory, focusing the speech's role in the construction of spatial thinking.

The starting point of this study is the absence of references in geography-focused school activities for the development of spatial thinking in preschool. Our main objective is to propose theoretical and methodological references for the spatial knowledge of children aged between 4 and 6 years old. The research is based on the following question: Which spatial abilities and concepts can be addressed in activities aimed at developing spatial thinking in children aged 4 to 6 years old?

To answer this question and achieve the main objective, the specific objectives were: a) to investigate and analyze the pertinence, possibilities and approaches regarding the spatial notions in children's education; b) develop teaching situations based on guiding theories about spatial thinking, children's drawing and the concept construction under a historical and cultural perspective; c) understand the patterns in children's graphic representations; and d) analyze the children's dialogues. Three series of activities with distinct objectives were proposed and analyzed as investigation instruments, based on the spatial thinking representation, concept, and abilities. All the activities addressed the central concept of location.

To develop the present research, we considered the relationship between spatial thinking, Geography and preschool education elements, once we addressed spatial relations and geographic principles from the perspective of representative problems and topics inserted in the childhood universe, mediated by language.

Language is known to be the essential factor in the cultural context, once it mediates culture. Regarding space, we understand that the cartographic language concretizes spatial thinking and is expressed in different ways during childhood, through gestures, speech, drawings, object handling, etc. Thus, the cartographic language expresses spatial content and thinking.

The present research adopted the conception of childhood as a social category, and the child is the subject of the right to acquire knowledge, in this case, spatial knowledge. 
Spatial thinking development in preschool education is based on this conception, once it allows the reflection on the space and issues involving spatial abilities, concepts and representations, since childhood, and these elements are critical for the reflection on one's place in the world, associated conditions and connections with other places. In this sense, preschool education environment can provide the development of spatial thinking in a systematized and intentional way.

Spatial thinking can be defined as a type of reasoning that involves concepts related to space, such as location, condition, connection, distance, proximity, graphic and tridimensional representations, spatial materialization through maps and scale models, thinking abilities and cognitive operations of the subjects regarding space and the comparison of places.

In the next point, we will present the investigation path, considering theoretical and methodological assumptions.

\section{School cartography and research}

\subsection{Methodology}

The objectives and this research object of this study are the interface between the Geographic Education, the representation of space and the skills of spatial thinking, as understanding how children establish spatial notions and represent the space allows us to discuss and examine ways to develop scientific literacy by Geography, that is, how can we introduce ways to solve problems through dialogue, creating hypothesis, observation, reflection, sorting etc.

The qualitative methodology based on the inductive data research guided the entire research process, from the conception of the problem dealt with, the collection and construction of data in the field until the analysis. When preparing our research question, we start with a theoretical framework on spatial thinking and the development of concepts in childhood, centered on the understanding of how children establish spatial relationships in a context close to them and also in relation to themes of Geography. The lack of theoretical and methodological support for preschool education related to Spatial Thinking is a problem, which may cause displacement of contents and practices developed in the initial years of Elementary Education for the minor children. In addition, the development of spatial thinking occurs in a progressive way and from a very early stage, from the observation and manipulation of objects, and later, by means of displacement in space, either by crawling or by standing, establishing the relationships front and behind, on one side and the other, and on the top and bottom.

These are spatial notions with which children begin to operate at home, in the mediation of adults and other children, but the school can develop these notions contextually, relating to space issues. Therefore, it is necessary to investigate spatial representations, spatial abilities as well as geographical principles through practical activities with children from five to six years of age.
This also justifies our main objective of proposing theoretical and methodological references for the spatial knowledge of children from five to six years of age, in order to contribute to cartography pertinent to childhood, based on the interaction of children and adults and the development of spatial thinking. When we use the term "theoretical-methodological references", we are referring to the dialogue between practical activities with children and the theory.

The central research questions is: which spatial concepts and abilities can be approached in activities aimed at the developments of spatial thinking in children aged between 4 and 6 years old?

To construct this research question, we worked from a theoretical body on spatial thinking and on the development of concepts in childhood, having as central point the understanding of how children establish spatial relations in their surrounding context and in relation to Geography themes.

To answers the research question and achieve our main objective, specific objectives constituted the guidelines for the development of the investigation:

a) Investigate and analyze spatial thinking pertinence, possibilities and approaches in preschool education.

Initially, the pertinence, the possibilities and the approach of the spatial notions were studied from the reading of official curricular references and, later, we come to understand them in the situations of education.

b) Develop teaching situations, based on the children's universe and on this research's guiding theories (GREIG, 2004; VIGOTSKI, 2009a; GERMEHL, 2008), allowing the creation of new forms of spatial representation.

The field of this investigation was structured from three sequences of activities with the central concept of location. The first activity deals specifically with the near space, that of living, while the other two mobilize geographic knowledge from distant aspects of their immediate experience, with the focus on Geosciences.

c) Analyze the patterns of the children's graphic representations.

Interpret and understand graphical representations, through the analysis of the establishment of spatial concepts for children and how they solve the problem of designing something three-dimensional, ie they deal with the volume of representation and organization of space.

d) Analyze the elements of spatial thinking inserted in the dialogues and argumentations.

Analyzing the children's interaction through gestures and speech, as well as their production, we found elements that show the construction of thinking, once both words and drawings are representations constructed upon reality.

The study of dialogue and graphic representations requires a qualitative methodology in data construction and analysis, ensuring coherence with the research objectives and theoretical references. Such methodology allows us to interpret the children's dialogues and identify which spatial thinking abilities are being developed in the activities proposed. 
We used a video camera for data collection. We conceived of this material as an essential instrument for the development of the whole research, once recording allowed us to capture the students gestures and speech with precision, registering what our memory or visual field are not able to apprehend (Carvalho, 2011). Moreover, the speech as students' representation is fundamental in this research, to comprehend how they analyze and conclude their activities, according to Vygotsky's view on the language theory and the role of words in spatial thinking development.

However, to establish the relation between the empiric activity and theory, the recordings must be transformed into data, in a process of sense construction that requires from the investigators the description of the nature of their interest throughout the whole investigation process, from the initial stages of research questions formulation to the final phases, in which the results are presented. (MARTINS, 2011, p. 300).

Transcriptions reveal the verbal interaction between the people involved, it is a type of technique that has speech as an aspect that alone does not ensure the manifestation of a meaning, which is constructed in the relations between discourses. To overcome this limit, we rely on the elaboration of maps of the multimodal discourse elaborated by Martins (2011), because there are forms of communication beyond speech, such as visual resources and gestural expressions.

Thus, based on Martins (2011), we mapped the recordings to extract relevant elements for the research, according to Table 1:

\begin{tabular}{|l|l|l|l|l|l|l|}
\hline \multirow{2}{*}{$\begin{array}{l}\text { Functional } \\
\text { Classificatio }\end{array}$} & \multirow{2}{*}{$\begin{array}{l}\text { Activit } \\
\mathrm{n}\end{array}$} & \multicolumn{3}{|l|}{ Semiotic modes } & \multicolumn{2}{l|}{ Central concepts } \\
\cline { 3 - 7 } & & $\begin{array}{l}\text { Verba } \\
1\end{array}$ & $\begin{array}{l}\text { Visua } \\
1\end{array}$ & $\begin{array}{l}\text { Gestural/Actio } \\
\mathrm{n}\end{array}$ & $\begin{array}{l}\text { Spatial } \\
\text { reasonin } \\
\mathrm{g}\end{array}$ & $\begin{array}{l}\text { Spatial } \\
\text { concept } \\
\mathrm{s}\end{array}$ \\
\hline & & & & & & \\
\hline
\end{tabular}

Table 1. Record mapping model adapted from Martins (2011, p. 311)

The map consists of a table composed of three main columns: functional classification, activity and semiotic modes. The first concerns the moment of a pedagogical activity, such as the organization of the room, introduction, revision and presentation of a theme. The second column, the activity, relates to the moments described in the first column, but can be classified according to its nature, as management - when we distribute the materials, we ask the children's attention to listen to a story or a question, or we propose the organization in groups - or conceptual reading activity, discussion or graphical representation of a problem. The third column systematizes the communication between the participants - not only through the speech, but we consider visual and gestural aspects. Although our research is based on Vygotsky's speech-centered studies, we recognize the importance of considering the visual and gestural aspects or the action, in addition to the verbal, mainly because the children from five to six years old, who still have little verbal repertoire and communicate easily in other ways.

We add the column "core concepts" in which we will identify the manifestations of spatial reasoning (skills) and spatial concepts, aspects of interest to answer our initial questions.

This is an important tool for the construction and analysis of data, and allows the identification and illustration of the activities. "Unquestionably, neither the map nor the transcription describes the sequence of events in the class in an objective and complete way; however, these tools indicate the significant elements regarding our specific interests." (MARTINS, 2011, p. 311).

Our main interest was to listen to the children and allow their interactions, aiming to understand how they establish spatial relations and which spatial thinking abilities are explored in the problems we presented in a sequence of activities.

The qualitative methodology bases the process of obtaining and interpreting data and dissemination, as the data were produced from records recorded by video recording, through their transcriptions and maps. The procedures for interpretation were based on the literature about spatial thinking and child development mainly, which allowed us to elaborate categories of analysis. In the next point, we will discuss the elaboration of each of the sequences of activities as instruments of data production for the research and how they can be developed for the purpose of mobilizing spatial thinking.

\subsection{Location and activity sequence}

For the development of activities with children, we considered the concept of spatial thinking as a form of reasoning formed by cognition, concepts and spatial representations.

\section{SPATIAL THINKING}

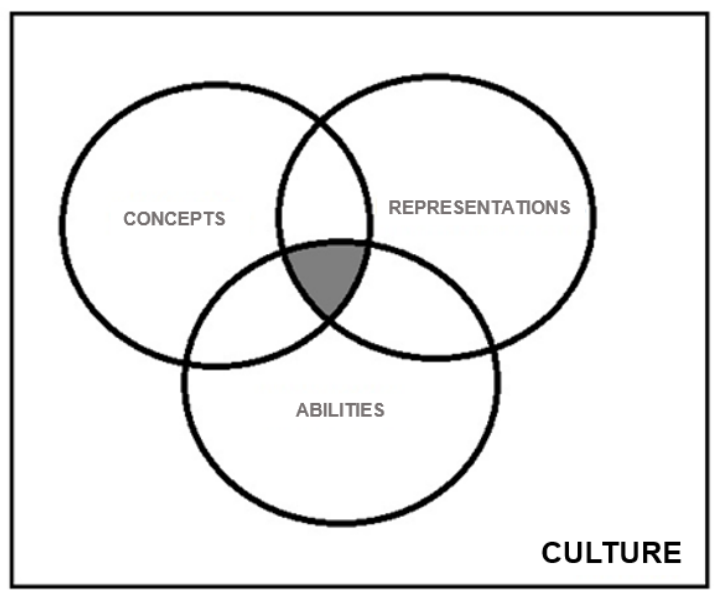

Figure 1. Spatial thinking inserted in culture (JULIASZ, 2017)

Spatial thinking abilities correspond to eight operations, according to Gersmehl $(2008,2014)$, as shown in Table 2. These processes occur in different parts of the brain and involve different memory networks; therefore, they do not correspond to an isolated type of intelligence.

\begin{tabular}{|l|r|}
\hline \multicolumn{2}{|l|}{ Basic Spatial Thinking } \\
\hline 1. Comparison & $\begin{array}{l}\text { bigger/smaller, rounder/squarer, } \\
\text { darker/lighter, redder/grayer. Examples: }\end{array}$ \\
\hline
\end{tabular}




\begin{tabular}{|c|c|}
\hline & $\begin{array}{l}\text { Iowa is smaller than Texas, Poland } \\
\text { rounder than Italy. China has more dots } \\
\text { than Australia on this map. Botswana has } \\
\text { a darker color than Zimbabwe. }\end{array}$ \\
\hline 2. Proximity & $\begin{array}{l}\text { next to, near, close to, within its area of } \\
\text { influence (its "aura"). Examples: cabin } \\
\text { near a lake, noisy house near an airport, } \\
\text { gas station near an interstate highway } \\
\text { exit, refugee camp near a country under } \\
\text { civil war. }\end{array}$ \\
\hline 3. Region & $\begin{array}{l}\text { part of a group of places with something } \\
\text { in common. Examples: farms with corn } \\
\text { fields in the Corn Belt, abandoned } \\
\text { factories in the Rust Belt, people } \\
\text { speaking Spanish in Latin America, }\end{array}$ \\
\hline 4. Sequence & $\begin{array}{l}\text { in order, along a line, on the way from } \\
\text { one place to another Examples: third } \\
\text { block along a particular street, grassland } \\
\text { between rainforest and desert, middle-age } \\
\text { houses between city and suburbs. }\end{array}$ \\
\hline 5. Hierarchy & $\begin{array}{l}\text { inside something larger. Examples: } \\
\text { counties inside a state, states inside a } \\
\text { country, creeks inside the watershed of a } \\
\text { large river, rivers or mountain ranges } \\
\text { inside a continent. }\end{array}$ \\
\hline 6. Analogy & $\begin{array}{l}\text { in a similar position in a different part of } \\
\text { the world. Examples: ports near mouths } \\
\text { of different rivers, neighborhoods near } \\
\text { downtown areas of different cities, places } \\
\text { in similar positions in different } \\
\text { continents. }\end{array}$ \\
\hline 7. Pattern & $\begin{array}{l}\text { arranged in bunches, lines, arcs, waves, } \\
\text { or other non-random ways. Examples: } \\
\text { forts in a line, coral reefs in a ring around } \\
\text { an island, oil wells in a bunch in one part } \\
\text { of a country, sand dunes arranged like } \\
\text { waves in a desert. }\end{array}$ \\
\hline 8. Association & $\begin{array}{l}\text { tending to occur together with specific } \\
\text { other features. Examples: stoplights at } \\
\text { major intersections, people with malaria } \\
\text { in places with A. mosquitoes, } \\
\text { earthquakes at borders between crustal } \\
\text { plates. }\end{array}$ \\
\hline
\end{tabular}

Table 2. Summary of spatial reasoning basic processes by Gersmehl (2014)

The investigation field was structured based on three sequences with the central concept of location. The first activity series deals specifically with the space nearby, the existence space, while the two other series are related to the geographic knowledge regarding distant aspects.

In order to analyze spatial thinking expression, we narrated the main outcomes of the activities, transcribed the video recordings, and mapped the resulting data according to our interests; i.e., verify the spatial concepts and abilities.

The first sequence had the main objective of understanding, through the identification of the places belonging to the way walked by the children, that this way - the whole - is composed of parts: the places.

In this specific proposal, we tried to develop the idea that the rooms are part of something bigger, the school, and that there is a transition between the places, i.e., a sequence of rooms. While elaborating this sequence, we considered as possible abilities the spatial comparison, hierarchy and transition (Table 3).

\begin{tabular}{l} 
Activity \\
\hline $\begin{array}{l}\text { How can we map the way from the gate to the classroom? } \\
\text { Representations: Mental Map }\end{array}$ \\
\hline \multicolumn{1}{c|}{ Sequence and development } \\
Objectives \\
Exercise the memory and create a map of the way from the \\
gate to the classroom; \\
Create graphic equivalents corresponding to the places and \\
objects
\end{tabular}

Table 3. Sequence of activities: What is the way from the gate to the classroom like?

The children maps correspond to the particular way they think the space and, in this research, are instruments to analyze the graphic spatial representations made by them in the school context. These representations allow children to write about their spaces and how they think about them, that is, the mental maps make it possible to materialize space according to a system of representation, which is the drawing.

The children map introduces notions of space representation, as well as the very idea of map as a social production, and in designing, children think about space, and certain geographical knowledge can be introduced.

The very idea of map presupposes the projection of the three dimensions of the terrestrial space on the plane, which also involves the conceptions of terrestrial and planetary surface. Joseph Nussbaum (1989) states that the 
planet as a sphere situated in an unlimited space does not correspond to an obvious conception of children, this is learned and developed over the years.

The research of Nussbaum (1989) clarifies the different conceptions of planet and the spatial notions from a cosmic body, fundamental factors for the geographic studies. We proposed a sequence of activities with the aim of mobilize the conception of the planet by children, considering the notions above and below, introducing the gravitational action through the use of materials such as the sphere, and the use of different materials that would problematize two visions in relation to the representation of space, the frontal and the vertical, from a curved line and also a base plane. In this sequence of activities, we use a children's story (SANTOS, 2000) because it problematizes the location of the characters on a planet, so we take the location as the central focus, in order to work on the conception that objects are located and there are conditions and connections between them.

Thinking about the planet and the presence of the characters on its surface also makes it possible to deal with the direction above and below, mobilizing the questions raised by Nussbaum (1989). Following this proposal, we put into action the thought about the existence of elements below the living surface of the children, focusing on the elementary notions of above and below, as well as involving the sequence ability of spatial thinking, that is, the idea of sequence from one space to the other, from the surface to the subsoil, from investigative activities, as shown in Table 5.

\begin{tabular}{|l|}
\hline \multicolumn{1}{|c|}{ Activity } \\
\hline Are there elements beneath the ground that we step on? \\
\hline \multicolumn{1}{|c|}{ Sequend development } \\
If there was no land, we would walk where? \\
Objective \\
Think about the importance and existence of the floor. \\
Materials \\
Text "If there was no land, we would walk where?", By \\
Ricardo Azevedo (2007); poster with "top" and "bottom"; \\
figures of elements like truck, crystal, dog, house, fossil of \\
dinosaur, tunnel and tree; plastic bags identified with "above" \\
and "below". \\
Dynamics \\
a) Talk about the question "If there was no land, we would \\
walk where?"; \\
b) reading the text "If there was no land, we would walk \\
where?" (AZEVEDO, 2007); \\
c) in groups, classification of figures into two different \\
categories: "above" and "below" of the ground; \\
c) presentation of the classification made by each group and \\
collage of the figures in the poster according to the \\
classification of the children; \\
d) Collective design of other elements that may exist under \\
the floor. \\
Sequence of activities: Are there elements beneath the ground \\
that we step on?
\end{tabular}

What lies under the bed and under the floor?
Objectives
Discuss and reflect on what may exist beneath the ground.
Materials
Book "Under the bed" (MANNING; GRANSTRÖN, 2007),
sulphite sheet and chalk.
Dynamics
a) talk about what may exist under the bed;
b) reading the book;
c) talk about what may exist under the bed and under the floor;
d) drawing on what lies beneath the ground;
e) conversation about the productions.
What is under the bed and under the earth?
Objective
Find the elements that may exist under the bed and floor.
Materials
Sheet with baseline and bed design with references.
Dynamics
a) conversation about the previous activity;
c) dalk about the drawings.
under the earth?" and the baseline with the bed design;

Table 5. Sequence of activities: Are there elements beneath the ground that we step on?

Thus, as in Geoscience, spatial concepts are also important and foundational for Geography, since they introduce themes and other concepts specific to geographic science. We want to affirm that our practical studies with children were based mainly on the concept of location beyond the mathematical space, trying to understand also the possibilities of Geographic Education and the development of spatial thinking.

\section{Conclusion}

Drawing consists in a language that concretizes and reflects spatial reasoning, involving important principles of Cartography and Geography. In this research, children are considered capable of learning, reflecting, creating, exchanging experiences, dialoguing, and teaching about the space.

The graphical representation through the drawing involves the relation between the concepts that the space includes, as distance and position and the abilities of the spatial thoughts, that are mobilized from a spatial problematic; as the child thinks about the arrangement of the elements in the graphic space, in an order, for example. The design of the space traveled allows to reflect and systematize a thought through the concretization of what is lived, creating symbols for each space object. The teacher who proposes activities of this type, allows to know how the children conceive and represent the space. 
The analysis of the research data allowed us to conclude that drawing is part of the cartographic initiation, and words are fundamental elements that concretize the way of thinking, in this case, spatial thinking ability. In this research, we reaffirm the direct relationship between Geography and the development of spatial thinking, considering the very nature of this Science, and Cartography as the language used to materialize this way of thinking. We defend the development of spatial thinking in children's education as a way to broaden the spatial knowledge and the construction of spatial concepts by the children.

Expanding spatial knowledge of the child is a task that the school can develop, so that in this research we seek to understand how we can create conditions that allow children to give meaning to their spatial experiences from Geography. Therefore, the activities treated here conceive the development of spatial knowledge not as a spontaneous process, on the contrary, we understand as a process that involves the development of the concept of space, of graphic representations and of the abilities of spatial thought, inserted in culture and interaction with the other.

\section{References}

GERSMEHL, P. J. Teaching Geography. New York: Guilford Press. 2008.

Basic Spatial Reasoning, 2014. Disponível em < http://www.ourspatialbrains.com/wp-

content/uploads/2015/07/Basic-Spatial-Reasoning.pdf> Acesso em: 15 jun. 2016.

GREIG, P. A criança e seu desenho: o nascimento da arte e da escrita. Tradução de Fátima Murad, Porto Alegre: Artmed, 2004. 248 p.

HANNOUN, H. El niño conquista el médio: atividades exploradoras em la escuela primaria. Tradução de Juan Jorge Thomas. Buenos Aires: Kapelusz,1977.

JULIASZ, P. C. S. O pensamento espacial na Educação Infantil: uma relação entre Geografia e Cartografia. Tese (Doutorado em Educação). Faculdade de Educação. Universidade de São Paulo, 2017.

MANNING, M.; GRANSTRÖN, B. Debaixo da cama: uma viagem ao centro da Terra. Tradução de Luciano Machado. São Paulo: Ática. 2007. 31 p. (Coleção Xereta).

MARTINS, I. Dados como diálogo: construindo dados a partir de registros de observação de interações discursivas em salas de aula de ciências. In: SANTOS, F. M. T. dos; GRECA, I. M. (Org.) A pesquisa em ensino de ciências no Brasil e suas metodologias. 2. ed. Injuí: Ed. Injuí, 2011, p. 297 - 321.

NUSSBAUM, J. La tierra como cuerpo cósmico. In: DRIVER, R; GUESNE, E. TIBERGHIEN, A. Ideas científicas em la infância y la. Madrid: Ediciones Morata. 1982, p. 259 - 290.

ORLANDI, E. P. Análise de discurso: princípios e procedimentos. 7. ed. Campinas (SP): Pontes, 2007
SANTOS, J. R. A Pirilampéia e os dois menino de Tatipurum. São Paulo: Editora Ática. 2000.

VIGOTSKI, L. S. A construção do pensamento e da linguagem. 2. ed. Tradução de Paulo Bezerra. São Paulo: Editora WMF Martins Fontes, 2009a.

Imaginação e criação na infância. Tradução de Zoia Prestes. São Paulo: Editora Ática, 2009b. 